\title{
Liver transcriptome analysis reveals important factors involved in the metabolic adaptation of the transition cow
}

\author{
N.-T. Ha, ${ }^{*}{ }^{1}$ C. Drögemüller,ł C. Reimer, † F. Schmitz-Hsu,§ R. M. Bruckmaier, ${ }^{*}$ H. Simianer,† and J. J. Gross ${ }^{*}$ \\ *Veterinary Physiology, Vetsuisse Faculty, University of Bern, 3001 Bern, Switzerland \\ †Animal Breeding and Genetics Group, Department of Animal Sciences, University of Goettingen, 37075 Goettingen, Germany \\ łInstitute for Genetics, Vetsuisse Faculty, University of Bern, 3001 Bern, Switzerland \\ §Swissgenetics, 3052 Zollikofen, Switzerland
}

\section{ABSTRACT}

During early lactation, dairy cows experience a severe metabolic load often resulting in the development of various diseases. The inevitable deficiency in nutrients and energy at the onset of lactation requires an optimal adaptation of the hepatic metabolism to overcome metabolic stress. We conducted a whole-liver transcriptome analysis for the transition cow to identify novel factors crucial for metabolic adaptation. Liver samples were obtained from 6 Red Holstein dairy cows (parity 2 to 7 , mean \pm standard deviation: $3.7 \pm 2.3$ ) at 3 time points: $\mathrm{T} 1=22 \pm 4 \mathrm{~d}$ antepartum, $\mathrm{T} 2=10 \pm 2 \mathrm{~d}$ postpartum, and $\mathrm{T} 3=17 \pm 2 \mathrm{~d}$ postpartum. Using RNA sequencing (RNA-seq), we studied the transcriptomic profile of the transition cow before and after parturition. We performed a differential gene expression analysis (DGEA) and gene-set enrichment analysis (GSEA) for biological processes (gene ontology, GO) and pathways (Kyoto Encyclopedia of Genes and Genomes, KEGG). Among the 10,186 expressed genes, we discovered 1,063 differentially expressed genes (false discovery rate $=$ $5 \%$ ). The GSEA revealed 16 biological processes and 7 pathways significantly (false discovery rate $=5 \%$ ) associated with the hepatic changes of the transition cow. Our results confirm that major hepatic changes are related to energy mobilization after parturition; in particular, they are related to fatty acid oxidation/metabolism, cholesterol metabolism, and gluconeogenesis. Using the STRING database (https://string-db.org/), we investigated interactions between significant genes and identified 9 key genes (CYP 7A1, APOA1, CREM, LOC522146, CYP2C87, HMGCR, FDFT1, SGLE, and $C Y P 26 A 1)$ through which the different processes involved in the metabolic adaptation interact. Comparing our main results with the literature, we could identify

Received December 14, 2016.

Accepted July 20, 2017.

${ }^{1}$ Corresponding author: nha@gwdg.de further genes that have not yet been associated with the transition period (e.g., CPT1B, ADIPOR2, LEPR, $C R E B 3 L 3$, and CCND1) and that are mainly involved in processes controlled by AMP-activated protein kinase, an important regulator of energy homeostasis.

Key words: RNA sequencing (RNA-seq), transition cow, metabolic adaptation, hepatic transcriptome

\section{INTRODUCTION}

The transition period of a dairy cow, mostly defined as the period from wk 3 antepartum until 3 wk postpartum, is characterized by abrupt changes in physiology, metabolism, and nutrition of the animal (Gross et al., 2011a,b). Intensive fetal growth before parturition, morphological and endocrine changes related to mammary gland development, and the tremendous increase in energy and nutrient demand with the onset of lactation are the most substantial challenges the dairy cow has to face during this period. Hence, optimal metabolic adaptation is required to avoid the development of metabolic and infectious diseases.

The liver is the key organ controlling and regulating metabolic adaptation. Therefore, several studies have been carried out to quantify the molecular adaptations during the transition period (e.g., Greenfield et al., 2000; Reynolds et al., 2003; Drackley et al., 2005; Loor et al., 2005; Graber et al., 2010; Schlegel et al., 2012; Ostrowska et al., 2013) to improve the understanding of the complexity of the transition cow's biology. The main purpose of these studies was to assess the transcriptomic profile of candidate genes known to be involved in liver metabolism during the transition period using mRNA abundances determined by real-time PCR (Greenfield et al., 2000; Graber et al., 2010; Schlegel et al., 2012; Ostrowska et al., 2013). Whereas most of these studies focused mainly on specific metabolic processes that are already known, a more extensive study conducted by Loor et al. (2005) that included the gene expression profiles of more than 6,300 genes using microarray technology. 
Table 1. Milk yield on test day, energy balance in the test week, and metabolic status of the 6 studied cows

\begin{tabular}{lccccc}
\hline & & & & \multicolumn{2}{c}{ Plasma concentration $(\mathrm{mmol} / \mathrm{L})$} \\
\cline { 5 - 6 } Period & $\begin{array}{c}\text { Day of sampling } \\
\text { (relative to parturition) }\end{array}$ & $\begin{array}{c}\text { Milk yield } \\
(\mathrm{kg})\end{array}$ & $\begin{array}{c}\text { Energy balance } \\
(\text { MJ of NE } / \mathrm{d})\end{array}$ & Glucose & \multirow{2}{*}{ Fatty acids } \\
\hline T1 & $-22 \pm 4$ & - & $26.0 \pm 12.7$ & $4.25 \pm 0.28$ & $0.17 \pm 0.05$ \\
T2 & $10 \pm 2$ & $31.6 \pm 2.2$ & $-42.8 \pm 7.9$ & $3.31 \pm 0.18$ & $0.80 \pm 0.21$ \\
T3 & $17 \pm 2$ & $35.5 \pm 3.0$ & $-34.5 \pm 14.7$ & $3.48 \pm 0.30$ & $0.76 \pm 0.34$ \\
\hline
\end{tabular}

According to our knowledge, the present study is one of the first using RNA-sequencing (RNA-seq) to investigate changes in the whole-liver transcriptome of dairy cows from late pregnancy to early lactation. This study may, first, validate the results established by earlier studies and, second, reveal new possible candidate genes crucial for the hepatic adaptation. A similar approach was taken by McCabe et al. (2012), who analyzed the whole-liver transcriptome using RNA-seq to compare cows divergent in negative energy balance (NEB). However, in practice, whether a cow can successfully adapt to the new physiological state of lactation may not depend only on the extent of NEB. Indeed, cows with an optimal adaptive performance could overcome even an extremely severe NEB without any occurrence of health disorders, whereas more vulnerable cows are more prone to fail even under less challenging situations (Kessel et al., 2008; van Dorland et al., 2009; Gross and Bruckmaier, 2015). Therefore, the present study aims to identify currently unconsidered factors involved in the achievement of metabolic adaptation in transition dairy cows.

\section{MATERIALS AND METHODS}

\section{Characterization of Cows and Liver Sampling}

Experimental procedures and sampling followed the guidelines of the Swiss Law on Animal Protection and were approved by the Veterinary Office of the Canton Fribourg, Switzerland. For our analysis, we collected liver and blood samples from 6 dairy cows (Red Holstein, parity 2 to 7 , mean \pm SD: $3.7 \pm 2.3$ ) at 3 stages: 3 wk before expected calving (T1, $22 \pm 4 \mathrm{~d}$ antepartum) and 2 wk (T2, $10 \pm 2 \mathrm{~d}$ postpartum) and 3 wk (T3, $17 \pm 2 \mathrm{~d}$ postpartum) after calving. Cows were kept at an experimental station with individual daily recording of feed intake and milk yield. Liver sampling was performed by blind percutaneous needle biopsy under local anesthesia as described by van Dorland et al. (2009). Liver samples were directly put in RNAlater (Ambion, Applied Biosystems, Austin, TX) and stored at $-80^{\circ} \mathrm{C}$ until extraction. We calculated energy balance (EB) of the animals weekly using milk yield, DMI, and development of BW. Blood samples obtained before liver sam- pling were analyzed for concentrations of glucose, fatty acids, and BHB to characterize the metabolic changes occurring during the transition period as described previously (Gross et al., 2011a). Apart from the liver samples, the 6 cows were also phenotyped for various traits and metabolic characteristics, shown in Table 1. Only 5 samples were collected at $\mathrm{T} 1$; one cow (cow 1) has no sample at $\mathrm{T} 1$ because of technical reasons.

\section{RNA Isolation and Sequencing}

RNA was isolated from liver samples using RNeasy Mini kit (Qiagen, Hombrechtikon, Switzerland). The quality and quantity of the isolated RNA was measured with an Agilent 2100 Bioanalyzer (Agilent Technologies, Basel, Switzerland) and Qubit 2.0 Fluorometer (Life Technologies, Zug, Switzerland). The RNA integrity number (RIN) of all samples was between 8.1 and 9.0. Approximately $800 \mathrm{ng}$ of high-quality RNA was used for strand-specific paired-end RNA library preparation (TruSeq stranded mRNA sample preparation guide Part \#15031047 Rev.D, Illumina, Zürich, Switzerland). Total mRNA libraries were multiplexed (pool of $4 \mu \mathrm{L}$ of each sample after dilution to $2 \mathrm{n} M$, adding $\sim 1 \%$ PhiX control) and sequenced each in 3 lanes (in the same run) on the Illumina HiSeq2000 platform using 2 $\times$ 100-bp paired-end sequencing cycles. The Illumina BCL output files with base calls and qualities were converted into FASTQ file format and demultiplexed with CASAVA (v1.8.2) software (Illumina).

\section{RNA Read Alignment and Counting}

To avoid bias in the subsequent analyses, we conducted comprehensive quality control using FastQC (version 0.11.2; Andrews, 2010) for the forward and reverse reads of the 3 lanes for all 17 samples. In general, none of the read sequences failed overall quality control; nevertheless, as a matter of course, some sequences contained bases with low quality scores $(<10$ Sanger Quality Score). To assess whether these outliers affected our analyses, we trimmed the bad bases for all samples using the program Trimmomatic (version 0.33; Bolger et al., 2014). After quality control, we combined the different lanes for each sample before 
mapping them to the reference genome Bos Taurus (UMD3.1, release 78; Zimin et al., 2009). For comparison purposes, we performed alignment on the original as well as trimmed samples using 2 programs: STAR (version 2.4; Dobin et al., 2013) and Tophat2 (version 2.0.13; Kim et al., 2013), based on a gene annotation (Bos Taurus, UMD3.1, release 78) downloaded from Ensembl (Flicek et al., 2013) to improve the mapping performance. STAR and Tophat were run with their default parameters, because both claim to be optimized for mammalian species (based on comparison of the corresponding manuals). Finally, we used featureCounts (version 1.4.6-p19; Liao et al., 2014) to count the number of reads overlapping with a specific gene. To avoid inflation of false positives, we only counted read pairs that were uniquely mapped in a concordance manner and could be unambiguously assigned to an annotated gene. The average rate of mapped pairs for STAR and Tophat was 0.94 and 0.80 , respectively, whereas the average rate of counted pairs was 0.74 for STAR and 0.64 for Tophat using untrimmed data. After trimming the data, the mapping and counting rate decreased to an average of 0.92 and 0.72 , respectively, using the program STAR. Supplemental Figure S1; (https://doi.org/10.3168/jds.2016-12454) illustrates the comparison between trimming vs. not trimming, and STAR vs. Tophat2. In our data, we detected that the effect of trimming is negligible, while STAR has a higher mapping rate than Tophat2 (Supplemental Figure S1; https://doi.org/10.3168/jds.2016-12454). Therefore, in the present paper, all results are based on the mapping program STAR for untrimmed data. The details of the mapping and counting programs are listed in Supplemental Table S1 (https://doi.org/10 $.3168 /$ jds.2016-12454). For the differential gene expression analysis, we only included genes with more than $1 \mathrm{cpm}$ (counts per 1 million reads) in all samples of at least one condition (T1, T2, or T3) to avoid unreliable results. Finally, a matrix with counts of 10,186 genes for 17 samples was available for further analyses.

\section{Differential Gene Expression and Gene Set Enrichment Analyses}

All analyses were performed in $\mathrm{R}$ ( $\mathrm{R}$ Core Team, 2014). We conducted a differential gene expression analysis (DGEA) comparing T1 versus T2 and T1 versus T3. Note that even though the sample of cow 1 at T1 was missing, cow 1 was included in the comparisons because it provided useful information for the estimation of relevant normalization factors. For the identification of genes differentially expressed before and after lactation, we used the R-package "edgeR" (Robinson et al., 2010; McCarthy et al., 2012) using a paired design to account for the baseline differences between the cows. For each gene $g$, we used a likelihood-ratio test ("glmFit") based on the generalized linear model:

$$
\log (Y)=\mathbf{X} \boldsymbol{\beta}+\log N
$$

where $\quad Y=\left(y_{T i, 1}, \ldots, y_{T i, n}, y_{T j, 1}, \ldots, y_{T j, n}\right)^{t} \quad$ and $N=\left(N_{T i, 1}, \ldots, N_{T i, n}, N_{T j, 1}, \ldots, N_{T j, n}\right)^{t}$ are the normalized gene counts and library sizes for each cow in $T i$ and $T j$, respectively; , where $\mathrm{x}^{t}$ denotes the transpose vector of $\mathrm{x} . \mathbf{X}$ is the design matrix with the columns Intercept and the binary designed variables Cow $_{1}, \ldots$, Cow $_{n}$, Time; and $\boldsymbol{\beta}$ is the vector of regression coefficients. Using the negative binomial distribution for the gene counts, we tested the null hypothesis that the coefficient $\beta_{\text {Time }}$ is equal to zero comparing $\mathrm{T} 1$ versus $\mathrm{T} 2$ and T1 versus T3. Note that we did not account for the parity of the different cows in our statistical model. In our experiment, each cow had a specific parity (from 2 to 7) and thus, the variable Cow can be viewed as a sub-group of parity. Therefore, the effect of parity on the gene expression, if existent, would be absorbed by the Cow effect and would not affect our estimation and testing of the Time effect.

We used the obtained $P$-values to perform a gene-set enrichment analysis (GSEA) based on the weighted Kolmogorov-Smirnov Test (WKS) suggested by Subramanian et al. (2005) to detect pathways and biological processes enriched with significant genes. Based on the Kyoto Encyclopedia of Genes and Genomes (KEGG) database (Kanehisa et al., 2012) and Gene Ontology (GO) database (Gene Ontology Consortium, 2015), we created gene to pathway/GO term annotations. As for the WKS, we made use of the weights $-\log _{10}\left(p_{j}\right)$, where $p_{j}$ is the $P$-value of the of gene $g_{j}$ obtained from the DGEA and 10,000 permutations. For further details, we refer to Ha et al. (2015) and Subramanian et al. (2005).

As for the KEGG pathways, we further conducted a signaling pathway impact analysis (SPIA) by Tarca et al. (2009). The SPIA approach consists of 2 independent steps: (1) an over-representation analysis (ORA) to determine whether a certain pathway is enriched with significant genes; and (2) a perturbation analysis (PEA) to capture the impact of gene expression changes to the considered pathway using its topology structure. In our study, we considered a combination of WKS and PEA (i.e., the second part of the SPIA). For each KEGG pathway, we obtain its final $P$-value by combining the $P$-values of WKS and PEA using Fisher's method (Mosteller and Fisher, 1948), which 
is given by $\mathrm{X}^{2}=-2\left(\ln p_{G S E A}+\ln p_{P E A}\right)$, where $\mathrm{X}^{2}$ is a random variable following a $\chi^{2}$ distribution with 4 degrees of freedom.

The PEA was conducted using the R-package "ToPASeq" (Ihnatova and Budinska, 2015), adapted for RNA-seq data. Because PEA is a network-based approach, it is only applicable for signaling pathways with gene network information (inhibition/activation). For those pathways where a perturbation analysis was not applicable, we only considered the $P$-values obtained from the WKS approach.

Both DGEA and GSEA require the testing of multiple null hypotheses and thus, need to be properly accounted for. Here, we used the false discovery rate (FDR) approach by Benjamini and Hochberg (1995). This method aims to keep the expected proportion of false positives (i.e., FDR) below a certain level $q$ by maximizing the significance level $\alpha$ such that the equation $\frac{\alpha m}{R(\alpha)} \leq q$ holds, where $m$ denotes the total number of tests and $R(\alpha)$ is the number of tests that were declared significant at level $\alpha$. For the KEGG pathway analysis, we reduced the multiple testing problems by filtering out non-relevant pathways, which are the KEGG pathways for human diseases.

To inspect the interaction between our significant genes, we used STRING 10 version 10.0 (https:// string-db.org/; Szklarczyk et al., 2015); STRING is a database of known and predicted protein-protein associations that have been established based on several information sources, including curated databases, experimental/biochemical data, PubMed abstracts, and others (Szklarczyk et al., 2015). Using the Ensembl gene identifiers of our significant genes as input parameter, we used STRING to search for proteins associated with these genes to connect them to interacting networks.

\section{RESULTS}

\section{RNA-Seq Data}

Before filtering and analyzing the RNA-Seq data, we performed a simple comparison between cows to avoid any bias resulting from outliers in the 17 samples. Indeed, when comparing the $\log _{2}$-fold changes of the gene counts in T3 versus T1 for the 5 cows, we discovered 2 cows with gene expression patterns differing substantially from the rest (Figure 1). Note that the sample for cow 1 at T1 is missing and hence, a comparison is not possible for this cow. We found 7 genes to be highly upregulated with fold changes $(\mathbf{F C})>500$ for cow 2 . The 7 upregulated genes in cow 2 were only expressed in T3. As for the gene expression analysis, we only considered genes that were expressed in all samples of at least one time point to avoid unreliable results. Hence, the sample of cow 2 in T3 was still included in the following analyses. We found cow 6 to have significantly downregulated genes with fold-changes up to 5,000. Indeed, the sample of cow 6 in T1 is an outlier. Supplemental Table S2 (https://doi.org/10.3168/jds.2016-12454) lists the genes that were highly overexpressed in $\mathrm{T} 1$ for cow 6. We performed a simple Wilcoxon rank-sum test to examine whether these genes were enriched in certain KEGG pathways (Kanehisa et al., 2012) and discovered many significant pathways involved in several human diseases and myocardial disorders (Supplemental Table S3; https://doi.org/10.3168/jds.2016-12454), suggesting these findings to have a biological background. Therefore, cow 6 seemed to be an outlier and we excluded it from the subsequent analyses. After checking for outliers, we filtered the remaining 14 samples to keep only genes with more than 1 count per one million reads in all samples of at least one condition, resulting in a set of 10,186 genes that are expressed in the bovine liver.

\section{Performance and Metabolic Status of Cows}

During late gestation at T1, EB of all cows was positive $\left(26.0 \pm 12.7 \mathrm{MJ}\right.$ of $\left.\mathrm{NE}_{\mathrm{L}} / \mathrm{d}\right)$ but became negative during $\mathrm{T} 2\left(-42.8 \pm 7.9 \mathrm{MJ}\right.$ of $\left.\mathrm{NE}_{\mathrm{L}} / \mathrm{d}\right)$ and $\mathrm{T} 3$ $\left(-34.5 \pm 14.7 \mathrm{MJ}\right.$ of $\left.\mathrm{NE}_{\mathrm{L}} / \mathrm{d}\right)$. As expected, $\mathrm{T} 2$ and T3 presented similar values, although EB was slightly higher in T3. This effect was not significant, although the changes from $\mathrm{T} 1$ to $\mathrm{T} 2$ and from $\mathrm{T} 1$ to $\mathrm{T} 3$ were significant with $P$-values of 0.0007 and 0.00009 , respectively. The changes in metabolic state of the 5 cows followed the typical pattern of a transition cow. With the onset of lactation, elevated plasma concentration of fatty acids and BHB were expected, coupled with a decline in plasma glucose concentration (Figure 2). Interestingly, plasma concentrations of fatty acids and BHB exhibited substantial between-cow variation in $\mathrm{T} 2$ and T3 compared with T1, indicating differences in their adaptive performance (Table 1 ).

\section{DGEA and GSEA}

As expected, the 2 comparisons yielded very similar results, emphasizing the metabolic and physiologic similarity of the second and third weeks postpartum when cows are experiencing a distinct NEB (Figure 3). The number of significantly differentially expressed genes (DEG) was 967 (493 upregulated) in T1 versus T2 and 493 (318 upregulated) in T1 versus T3, respectively, at a FDR of 5\% (see Supplemental Tables S4 and S5; https://doi.org/10.3168/jds.2016-12454), of which 397 genes were significant in both comparisons. 
Considering the limited number of animals in our study, we will focus our subsequent only on robust results. Among the DEG, we found 196 unique genes (179 in $\mathrm{T} 1$ vs. T2 and 105 in $\mathrm{T} 1$ vs. T3) to have a FC $>2$ in at least 1 of the 2 comparisons, meaning that the corresponding gene expression level was more than doubled or halved after parturition. Using this set of DEG, we compared our results with former studies on the hepatic adaptation of dairy cows (Loor et al., 2005; Graber et al., 2010; Schlegel et al., 2012; Ostrowska et al., 2013) and an RNA-seq analysis for dairy cows with divergent energy balances (McCabe et al., 2012). We are aware that there are many more studies on the metabolic adaptation with other candidate genes. However, we chose the 4 cited studies (Loor et al., 2005; Graber et al., 2010; Schlegel et al., 2012; Ostrowska et al., 2013) because they measured gene expression changes in the transition cow without any experimental interventions; that is, with no further aggravation of the lactation-induced (i.e., physiological) NEB or special diets. We selected the study of McCabe et al. (2012) because it was the first study on the transition cow using RNA-seq. As can be seen from Figure 4, our results correlate highly with those of McCabe et al. (2012), with 53 genes in common. The 7 known genes that have been previously associated with the transition cow are FGF21, PC, HMGCR, ACSL1, HMGCS1, LDHB, and $C Y P^{\text {7A }}$ 1. Compared with the 5 mentioned studies, 138 genes were unique to our study, among which GPX3,
LOC104968645, APOA4, GOS2, and APOA1 were the most upregulated genes and $C G N 1, H B B, X P N P E P$, TEX12, and $L O C 785540$ were the most downregulated genes. In the following, we will refer to those 138 genes as the set of genes specific to our study.

The majority of the DEG were related to known processes occurring after calving; for example, the mobilization of lipids. This is reflected by results of the GSEA for GO terms (Table 2), where we found 4 and 15 biological processes to be significant in $\mathrm{T} 1$ versus $\mathrm{T} 2$ and $\mathrm{T} 1$ versus $\mathrm{T} 3$, respectively, at an FDR of $5 \%$. We found several significant GO terms to be linked to lipids (lipid metabolic process, storage, transport) and cholesterols (cholesterol efflux, homeostasis, biosynthetic process, metabolic process) as well as to other relevant biological processes such as "positive regulation of glucose import," "oligodendrocyte differentiation," "steroid metabolic process," and "isoprenoid biosynthetic process" (see Table 2).

The combined analysis of GSEA and PEA for KEGG pathways revealed 6 and 4 pathways that were significant (FDR $<0.05)$ in the comparisons $\mathrm{T} 1$ versus $\mathrm{T} 2$ and $\mathrm{T} 1$ versus $\mathrm{T} 3$, respectively, of which 3 were significant in both comparisons. Table 3 lists the details of the GSEA for all significant pathways. Similar to the GSEA results of the GO terms, we found pathways that have been associated with the transition cow before (e.g., "citrate cycle," "steroid hormone biosynthesis," "galactose metabolism") as well as other pathways such

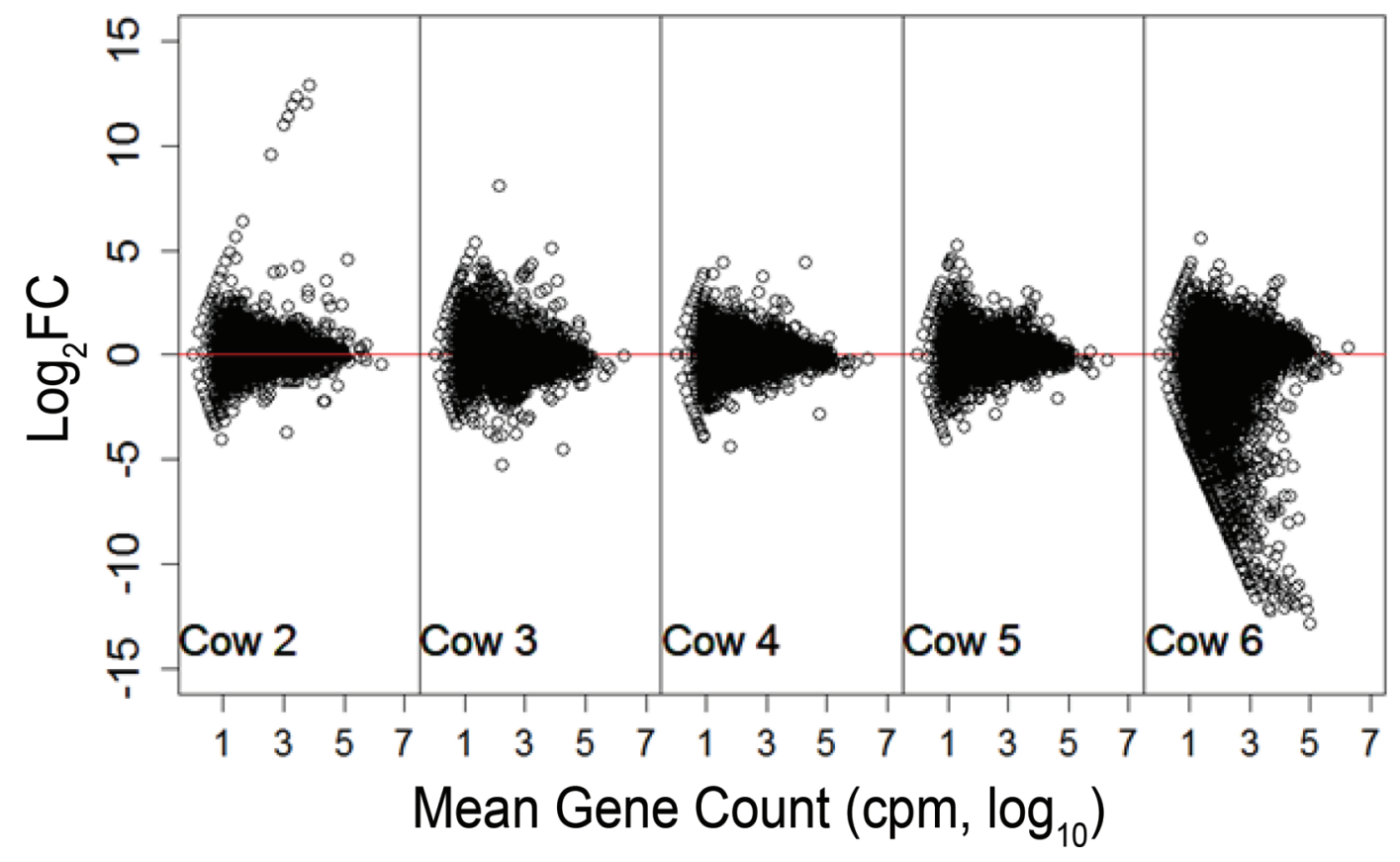

Figure 1. $\log _{2}$-fold changes $\left(\log _{2} \mathrm{FC}\right)$ of the gene counts for all genes in T3 (17 $\pm 2 \mathrm{~d}$ postpartum) compared with T1 (22 $\pm 4 \mathrm{~d}$ antepartum). The x-axis depicts the logarithm of the mean gene counts (counts per 1 million reads, cpm). Color version available online. 

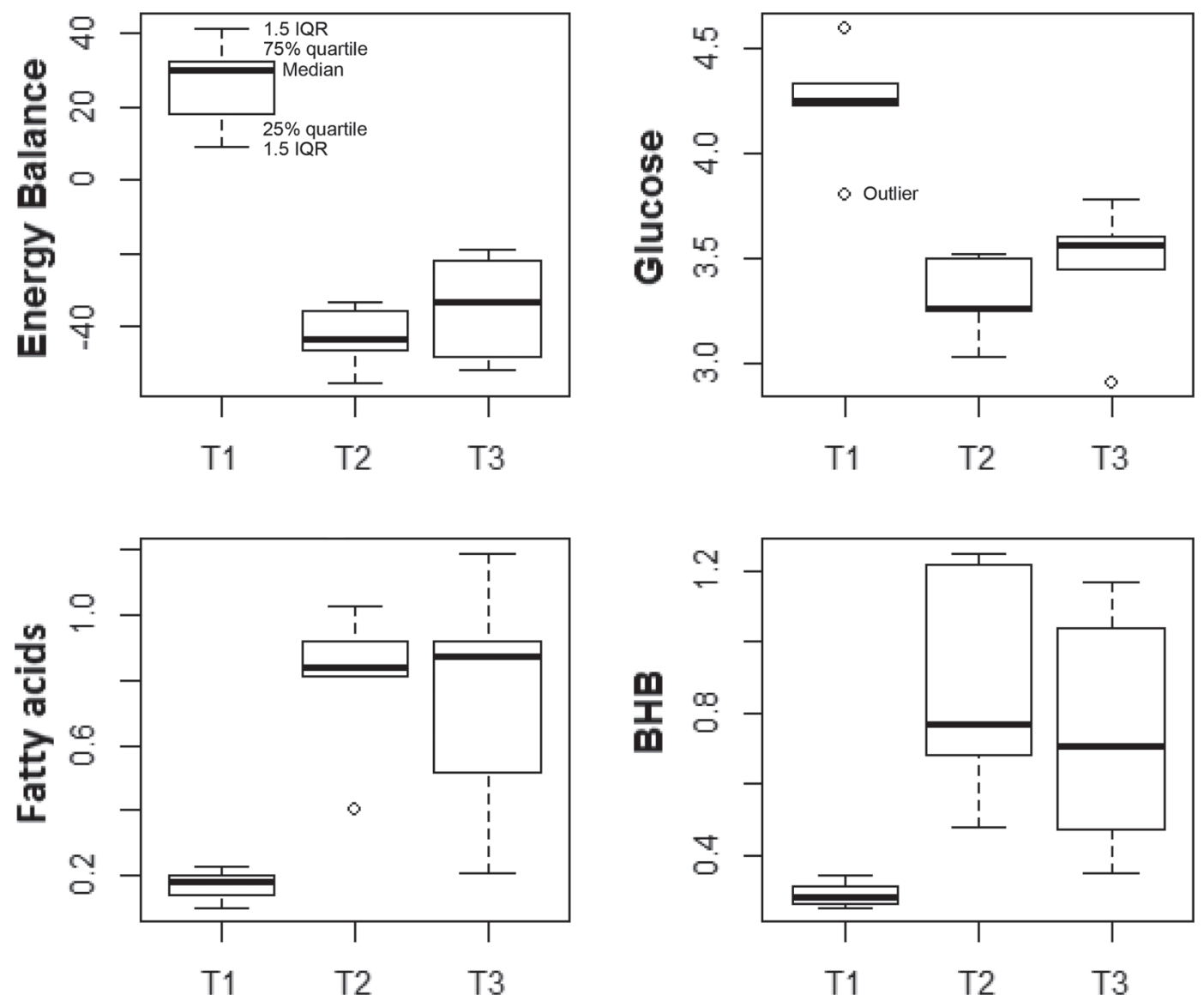

Figure 2. Boxplots of energy balance (EB, MJ of $\left.\mathrm{NE}_{\mathrm{L}} / \mathrm{d}\right)$ and plasma concentrations $(\mathrm{mmol} / \mathrm{L})$ of fatty acids, BHB, and glucose for the 6 studied cows in T1 ( $22 \pm 4 \mathrm{~d}$ antepartum), T2 (10 $\pm 2 \mathrm{~d}$ postpartum), and T3 (17 $\pm 2 \mathrm{~d}$ postpartum).

as the "adipocytokine signaling pathway." A detailed list of results for all pathways is given in Supplemental Tables S6 and S7 (https://doi.org/10.3168/jds.2016 -12454) for the comparisons T1 versus T2 and T1 versus T3, respectively. Note that PEA is only applicable for signaling pathways with existing gene interaction information. Among the 7 significant pathways, only one - adipocytokine signaling pathway - had gene network information for the perturbation analysis.

\section{Interaction Network Among DEG}

Using the robust set of 196 DEGs with FC $>2$ as input information, we inspected possible interactions between them using the STRING database (Szklarczyk et al., 2015). Among the 196 DEG, we found 83 DEG to interact with each other, resulting in 110 protein-protein associations; that is, these proteins jointly contributed to a shared function; Figure 5 shows this interaction network. It is important to underline that these associations are not established based on our RNA-seq data but are provided by the STRING data- base based on several information sources (Szklarczyk et al., 2015). Depending on the type of information, these protein-protein associations may have different levels of confidence, which are reflected by the width of the corresponding edges (see Figure 5).

According to Figure 5, the 83 DEG can be divided into one large network consisting of 64 DEG and 8 small networks. Key players in the large network were CYP7A1, APOA1, CREM, LOC522146, CYP2C87, HMGCR, FDFT1, SGLE, and CYP26A1, each having more than 5 interactions with other DEG. Interestingly, the 4 genes FDFT1, CYP7A1, LOC522146, and $C Y P 2 C 8 \%$, all upregulated after parturition, were directly linked to each other and together they interacted with 17 other DEG. To examine the part of the network that is specific to our study compared with the 5 former studies on metabolic adaptation (Loor et al., 2005; Graber et al., 2010; McCabe et al., 2012; Schlegel et al., 2012; Ostrowska et al., 2013), we reconstructed the network based on the set of 138 DEG specific to our study; this reduced network is displayed in Figure 6. As can be seen from Figure 6, the large network has been 
Time 2 vs. 1

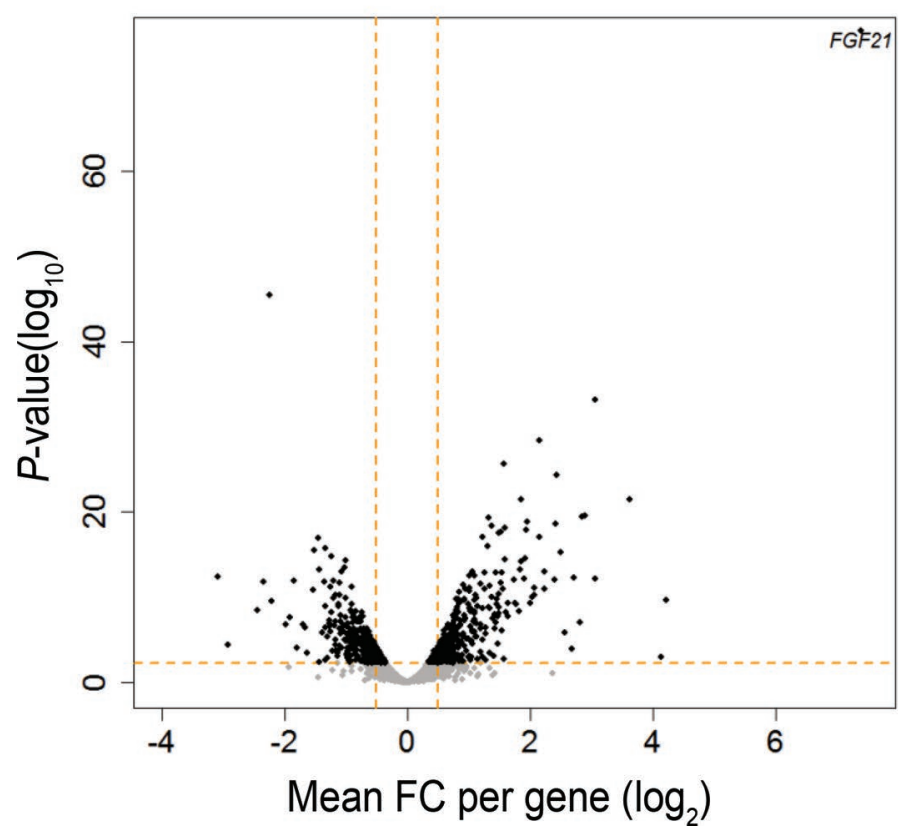

Time 3 vs. 1

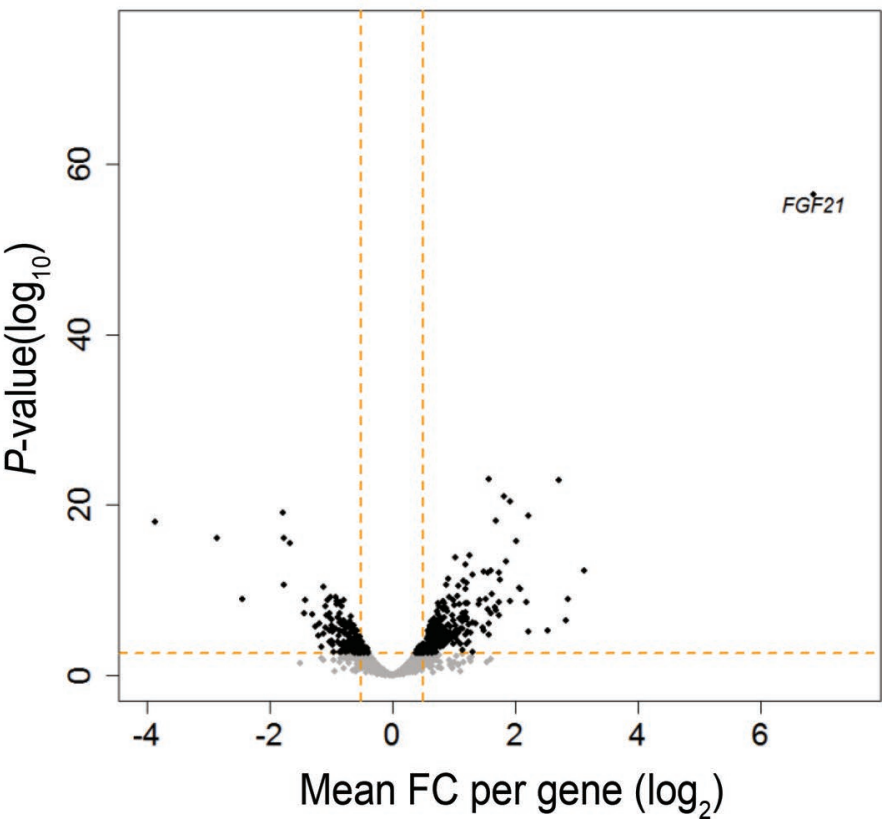

Figure 3. Volcano plots of the results of the differential gene expression analysis. Each dot in the plot represents a gene with its corresponding $\log _{2}$-fold change (FC) on the x-axis and $P$-value $\left(\log _{10}\right)$ on the y-axis. The horizontal line indicates the significance threshold (false discovery rate $<5 \%$ ), whereas the vertical line segregates genes with $\log \mathrm{FC}>1.5$. Time $1=22 \pm 4 \mathrm{~d}$ antepartum; Time $2=10 \pm 2 \mathrm{~d}$ postpartum; Time $3=17 \pm 2 \mathrm{~d}$ postpartum. Color version available online.

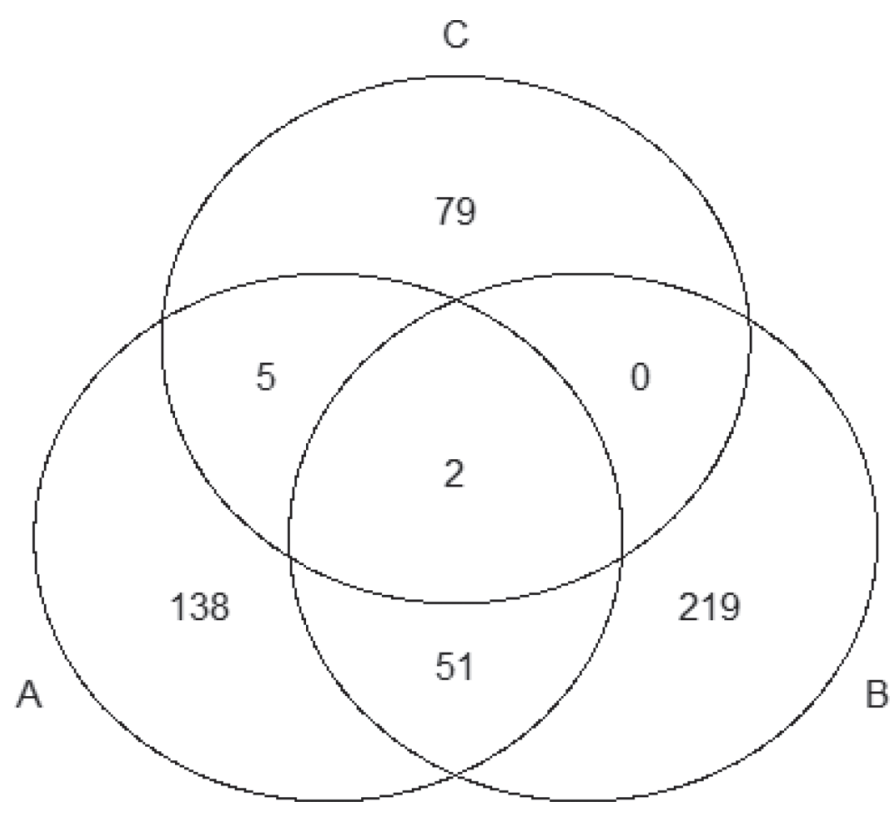

Figure 4. Venn diagram of the comparison of (A) our results with (C) former studies on the hepatic adaptation of dairy cows (Loor et al., 2005; Graber et al., 2010; Schlegel et al., 2012; Ostrowska et al., 2013), and (B) a RNA-seq analysis for dairy cows with divergent energy balances (McCabe et al., 2012). For our study, the numbers refer to the set of 196 significant genes (false discovery rate $=5 \%$ ) with fold-changes $>2$. divided into 3 sub-networks, which was mainly due to the exclusion of the key gene $C Y P^{r}$ /A1 that interacted with 10 other DEG in the full network (Figure 5). The STRING output further found 3 significant KEGG pathways to be enriched within this reduced network at an FDR of 5\%; namely, "arachidonic acid metabolism," "AMPK signaling pathway," and "retinol metabolism."

\section{DISCUSSION}

\section{Statistical Analysis}

We performed differential gene expression analysis using the R-package "edgeR" followed by 2 pathway analyses; namely, GSEA by Subramanian et al. (2005) and SPIA by Tarca et al. (2009). We are aware that our study is limited in the number of animals; this is because next-generation sequencing technology is still a relatively expensive tool. However, small sample sizes are common in RNA-seq experiments, and recent comparison studies (see e.g., Seyednasrollah et al., 2015; Schurch et al., 2016) have aimed at assessing the general effect of small sample sizes in such studies. Seyednasrollah et al. (2015) observed an appropriate power when the number of replicates (i.e., the number of samples per condition) is 5 or more. Schurch et al. (2016) pointed out that for the detection of highly dif- 
Table 2. Results of the gene-set enrichment analysis (GSEA) for the significant gene ontology (GO) terms (false discovery rate $<5 \%$ ) in T1 versus T2 and T1 versus T3 with their number of annotated genes and $P$-values ${ }^{1}$

\begin{tabular}{lrlll}
\hline GO term & Size & Score & P-value & Description \\
\hline T1 vs. T2 & 13 & 0.768448135 & 0 & \\
GO:0046326 & 9 & 0.776603805 & 0 & $\begin{array}{l}\text { Positive regulation of glucose import } \\
\text { GO:0048709 }\end{array}$ \\
GO:0055085 & 217 & 0.444286428 & 0 & Transmembrane transport \\
GO:0019915 & 17 & 0.68571022 & $1.00 \mathrm{E}-04$ & Lipid storage \\
T1 vs. T3 & & & \\
GO:0006629 & 140 & 0.428704927 & 0 & Lipid metabolic process \\
GO:0008202 & 20 & 0.686314502 & 0 & Steroid metabolic process \\
GO:0008203 & 39 & 0.609936639 & 0 & Cholesterol metabolic process \\
GO:0016126 & 12 & 0.765516241 & 0 & Sterol biosynthetic process \\
GO:0033344 & 18 & 0.667838555 & 0 & Cholesterol efflux \\
GO:0042632 & 39 & 0.596007269 & 0 & Cholesterol homeostasis \\
GO:0043401 & 32 & 0.622935816 & 0 & Steroid hormone mediated signaling pathway \\
GO:0046326 & 13 & 0.788161497 & 0 & Positive regulation of glucose import \\
GO:0055085 & 217 & 0.418976998 & 0 & Transmembrane transport \\
GO:0006869 & 35 & 0.564189542 & $1.00 \mathrm{E}-04$ & Lipid transport \\
GO:0008299 & 10 & 0.780301539 & $1.00 \mathrm{E}-04$ & Isoprenoid biosynthetic process \\
GO:0019915 & 17 & 0.705845036 & $1.00 \mathrm{E}-04$ & Lipid storage \\
GO:0033700 & 6 & 0.874227823 & $1.00 \mathrm{E}-04$ & Phospholipid efflux \\
GO:0006695 & 16 & 0.682434931 & 0.00019998 & Cholesterol biosynthetic process \\
GO:0042157 & 15 & 0.702350959 & 0.00019998 & Lipoprotein metabolic process \\
\hline
\end{tabular}

${ }^{1} \mathrm{~T} 1=22 \pm 4 \mathrm{~d}$ antepartum; T2 $=10 \pm 2 \mathrm{~d}$ postpartum; T3 $=17 \pm 2 \mathrm{~d}$ postpartum.

ferentially expressed genes (e.g., FC >2), 3 replicates may be sufficient, whereas an appropriate power to detect $\sim 90 \%$ of true effects would only be possible with more than 12 replicates. Considering these results, it is likely that we have missed some important genes that may have relevant effects on the hepatic adaptation of dairy cows.

In our pathway analysis, we used the SPIA approach consisting of 2 independent analyses. The main idea, hereby, is that changes in expression of upstream genes, which regulate the functions of other genes or interact with them, have a higher probability to affect the function of the pathway than downstream genes. The final
$P$-value for a pathway derives from the combination of the ORA and PEA. However, the ORA method implemented by Tarca et al. (2009) uses Fisher's exact test that requires a declaration of an arbitrary significance threshold for the differentially expressed genes, which, however, could exclude potentially informative genes, a well-known drawback of ORA approaches. To this end, Subramanian et al., (2005) introduced the GSEA approach to overcome these limitations by ranking all genes according to their strength of association (e.g., $P$-value or FC). Therefore, in our study, we considered a combination of the 2 approaches to make use of their advantages.

Table 3. Results of the gene-set enrichment analysis (GSEA) and perturbation (Pert) analysis ${ }^{1}$ for the 7 significant pathways (false discovery rate $<5 \%$ ) in T1 versus T2 and T1 versus T3 with their number of annotated genes and $P$-values ${ }^{2}$

\begin{tabular}{|c|c|c|c|c|c|c|}
\hline Pathway & Size & GSEA score & GSEA $P$-value & Pert Factor & Pert $P$-value & Combined $P$-value \\
\hline \multicolumn{7}{|l|}{ T1 vs. T2 } \\
\hline Steroid hormone biosynthesis & 38 & 0.59 & $1.00 \mathrm{E}-04$ & 0 & $\mathrm{NA}^{3}$ & $1.00 \mathrm{E}-04$ \\
\hline Arachidonic acid metabolism & 34 & 0.60 & 0.0002 & 0 & NA & 0.0002 \\
\hline Retinol metabolism & 36 & 0.57 & 0.0004 & 0 & NA & 0.0004 \\
\hline Adipocytokine signaling pathway & 46 & 0.54 & 0.0002 & 2.87 & 0.23 & 0.0005 \\
\hline Galactose metabolism & 17 & 0.67 & 0.0008 & 0 & NA & 0.0008 \\
\hline Linoleic acid metabolism & 16 & 0.64 & 0.0015 & 0 & NA & 0.0015 \\
\hline \multicolumn{7}{|l|}{$\mathrm{T} 1$ vs. T3 } \\
\hline Steroid hormone biosynthesis & 38 & 0.55 & 0.0004 & 0 & NA & 0.0004 \\
\hline Arachidonic acid metabolism & 34 & 0.54 & 0.0009 & 0 & NA & 0.0009 \\
\hline Adipocytokine signaling pathway & 46 & 0.50 & 0.0021 & 4.31 & 0.048 & 0.0010 \\
\hline Citrate cycle (tricarboxylic acid cycle) & 28 & 0.56 & 0.0012 & 0 & NA & 0.0012 \\
\hline
\end{tabular}

${ }^{1}$ Note that a perturbation analysis is only applicable for pathways with gene network information available.

${ }^{2} \mathrm{~T} 1=22 \pm 4 \mathrm{~d}$ antepartum; $\mathrm{T} 2=10 \pm 2 \mathrm{~d}$ postpartum; $\mathrm{T} 3=17 \pm 2 \mathrm{~d}$ postpartum.

${ }^{3}$ Not applicable. 


\section{DGEA and GSEA}

The key organ of metabolic adaptation during the transition period of dairy cows is the liver. Its role is to maintain an optimal balance between fuel mobilization, processing, and usage, which is crucial for successful adaptation to the elevated energy needs of the cow during this period. In our study, we conducted a whole-liver transcriptome analysis to gain more insight into the main processes linked to metabolic adaption. Our aim was to study changes of the hepatic transcriptome from late gestation to early lactation, not its actual state at a given point of time, which may differ between individual cows. Therefore, liver samples were collected from the same cows at different points in time. Subsequently, it was important to choose a statistical model that accounted for the baseline differ- ences between cows in a certain point of time and not only considering them as independent measurements (see Material and Methods section). For comparison, we also tested a statistical model without accounting for the baseline differences, which resulted in a lower number of significant DEG, even though the main results were similar.

The results of DGEA and GSEA showed strong consistency between our findings and the literature on the transition cow. Particularly, we found that most of the upregulated genes and significant pathways were related to mobilization of lipids and cholesterol and glucose metabolism, including the upregulation of the gene FGF21, which has been recently shown to be essentially involved in the regulation of the somatotropic axis (Carriquiry et al., 2009; Khan et al., 2014), and energy metabolism; for example, gluconeogenesis and

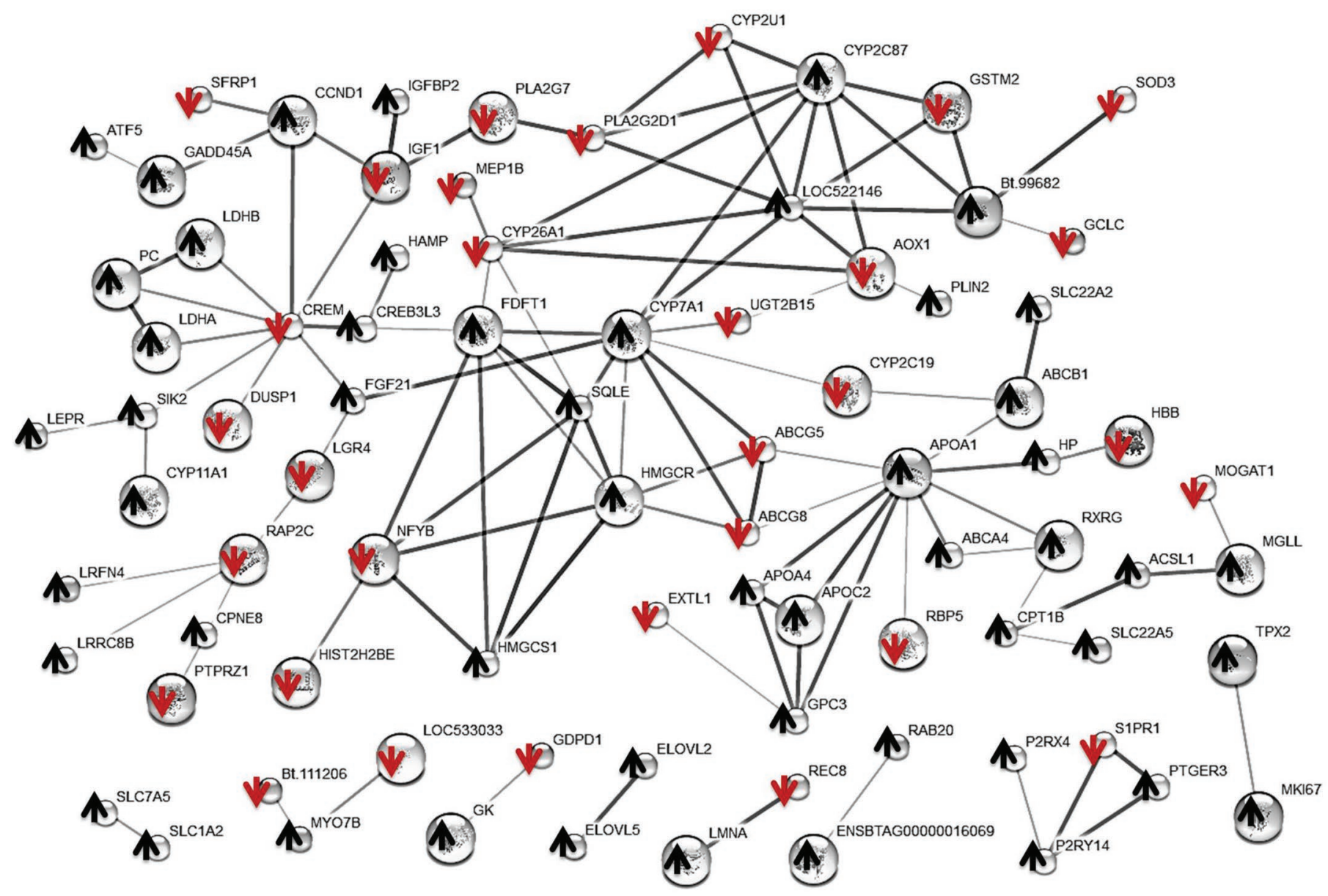

Figure 5. The STRING (https://string-db.org/) output of the interaction analysis based on the set of 196 significant genes with fold changes $>2$. Nodes are proteins encoded by our significant genes and the edges represent protein-protein associations that are meant to be specific and meaningful; that is, proteins jointly contribute to a shared function. The thickness of the edges indicates the strength of data support for this association (note: in this case "data" refers to the data in the STRING database, not our RNA-seq data). Small nodes are proteins of unknown 3-dimensional structures, whereas the 3D structures of large nodes are known or predicted. This graph only includes genes with at least one interaction with another gene. All other disconnected genes have been removed from the graph. The arrows indicate whether the corresponding genes were up- or downregulated after parturition in our RNA-seq analysis. Color version available online. 
$\beta$-oxidation of free fatty acids (Schlegel et al., 2013; Akbar et al., 2015). Further examples are the pathway "steroid hormone biosynthesis" that has been associated with the state of NEB of the transition cow (McCabe et al., 2012), and the "adipocytokine signaling pathway," which was shown to play a key role in lipid metabolism and feed efficiency (Xi et al., 2015).

Considering the results of the GSEA, our results agree strongly with other studies on the transition cow. However, when considering the results of the DGEA, we found only a small fraction of our significant DEG to coincide with the literature (Figure 4) when considering only studies without any experimental interventions. Among the DEG specific to our study, GPX3 was the most upregulated gene $\left(P=8.53^{-11}, \mathrm{FC}>12\right)$. As a member of the glutathione peroxidase enzyme family, GPX3 is an important defense mechanism against oxi- dative stress by protecting cells from oxidative damage (Mills, 1957). Indeed, several studies have considered oxidative stress to be a major factor for the success of metabolic adaptation (Bernabucci et al., 2005; Sharma et al., 2011). In particular, Sordillo and Aitken (2009) emphasized the need to enhance the antioxidant defense mechanisms of dairy cows during the transition period. In another study, Akbar et al. (2013) reported upregulation of GPX3 expression during feed restriction in mid-lactating cows. In fact, our data exhibited a significant negative correlation between the GPX3 expression pattern (log-transformed) and EB (T2 and T3) with a sample correlation of $-0.73(P=0.007)$. This suggests that cows with a higher energy deficit were exposed to a higher rate of oxidative stress and thus exhibited a higher level of plasma glutathione peroxidase enzymes.

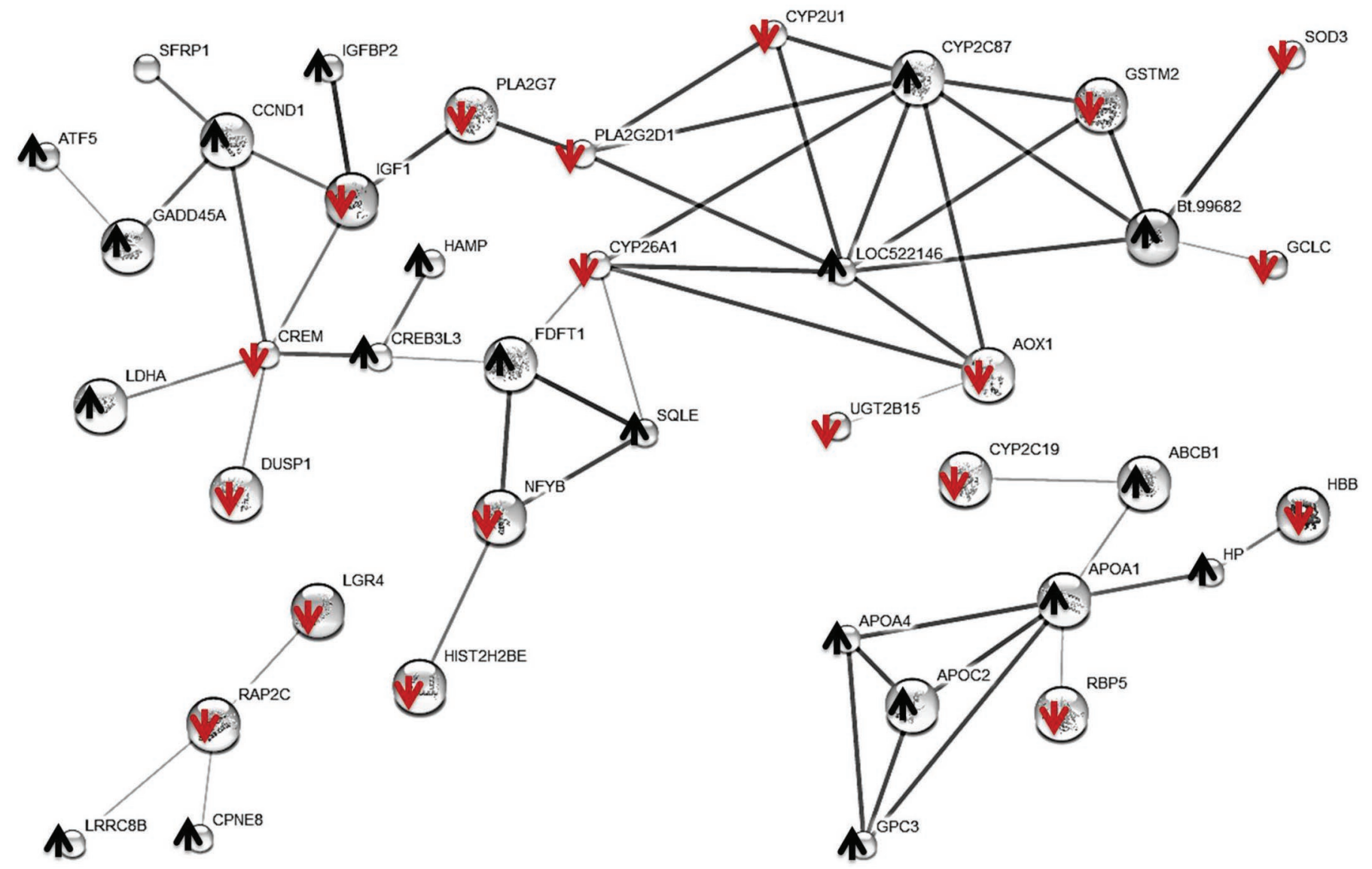

Figure 6. The STRING (https://string-db.org/) output of the interaction analysis based on the set of 136 significant genes with fold changes $>2$ that are specific to our study compared with 5 other studies on the transition cow. Nodes are proteins encoded by our significant genes and the edges represent protein-protein associations that are meant to be specific and meaningful; that is, proteins jointly contribute to a shared function. The thickness of the edges indicates the strength of data support for this association (note: in this case "data" refers to the data in the STRING database, not our RNA-seq data). Small nodes are proteins of unknown 3D structures, whereas the 3-dimensional structures of large nodes are known or predicted. This graph only includes genes with at least one interaction with another gene. All other disconnected genes have been removed from the graph. The arrows indicate whether the corresponding genes were up- or downregulated after parturition in our RNAseq analysis. Color version available online. 
Other highly upregulated genes that were specific to our study are APOA1 and APOA4, both known to be related to cholesterol (UniProt Consortium, 2017) and G0S2. The G0/G1 switch 2 gene (G0S2) is known to be an inhibitor of adipose triglyceride lipase (Zhang et al., 2014). In mice, the knockdown of this gene has been associated with an increased ketogenesis, accelerated gluconeogenesis, and decelerated glycogenolysis (Zhang et al., 2014). Moreover, Zhang et al. (2014) suggested that G0S2 was involved in the control of adaptive energy response to fasting in mice. Considering their results and the upregulation of this gene after calving in our study, G0S2 may have a similar role in the transition cow, which might be related to the excessive energy mobilization.

\section{Insight from Interactions Among Significant Genes}

The results of the STRING analysis underlined the complexity of the metabolic adaptation in form of a highly interconnected network. The STRING output clearly showed that our set of DEG was biologically connected because it had more intra-set interactions than would be expected in a random set of genes. This was true for the networks that we obtained based on the full set of 196 DEG $(P$-value $=0$, Figure 5$)$ and the reduced set of 138 DEG containing genes specific to our study $\left(P\right.$-value $=2.35 \times 10^{-11}$, Figure 6$)$.

Comparing the 2 networks, we can see that our current understanding of the transition cow is far from complete. It is important to note that we only compared our results with those studies that measured gene expression changes from late pregnancy to early lactation without any experimental interventions. The reduced network might reflect the parts of metabolic adaptation that remain to be explored, because it consists of genes that have not previously been associated with the transition cow. According to the STRING output, 3 pathways are significantly enriched within this reduced network including the AMPK signaling pathway, which was not significant in the results of the GSEA for all genes (see Table 3). This pathway is known to play an important role in the regulation of lipid metabolism in hepatocytes (Deng et al., 2015) and is one of the main processes important for the metabolic adaptation.

Within the large network of Figure 5, we could identify 9 key DEG that highly interacted with other genes. Among the 9 key DEG, only 2 (HMGCR and CYP7A1) have been associated with the transition cow before (e.g., Graber et al., 2010; McCabe et al., 2012). Interestingly, 5 out of 9 key DEG (HMGCR, CYP7A1, APOA1, FDFT1, and SGLE) are related to cholesterol synthesis. In particular, the proteins encoded by FDFT1 (squalene synthase) and $S G L E$ (squalene monooxygenase) are involved in biosynthesis of lanosterol, an intermediate metabolite of cholesterol biosynthesis. This result again confirms that the liver is reacting to the increased demand for cholesterol after parturition (Kessler et al., 2014). Other key DEG were CREM (known to be involved in spermatid maturation), LOC522146 (an uncharacterized protein), and CYP2C87 and CYP2C19, which belong to the cytochrome p450 superfamily. Unfortunately, we could not establish relationships between the functionality of these genes and metabolic adaptation. However, their high connectivity within our network (Figure 5) and their interactions with other DEG indicate that they are important genes through which the different processes of the metabolic adaptation interact. Therefore, we hypothesize that they might also have an important role in these processes, which should be investigated in further studies.

The STRING output also provides insights into how different aspects of the metabolic adaptation are related to each other. As an example, we might consider the 2 partial networks: (1) the block containing $C P T 1 B$ (carnitine O-palmitoyltransferase 1, muscle isoform), ACSL1 (long-chain-fatty-acid-CoA ligase 1), $M G L L$ (monoglyceride lipase), and MOGAT1 (2-acylglycerol O-cyltransferase 1); and (2) the block consisting of APOA 1 (apolipoprotein A-I), APOA4 (apolipoprotein A-IV precursor), and APOC2 (apolipoprotein C-II). Whereas all the genes of the first block can be related to fatty acid oxidation and metabolism, the genes of the second block are all associated with cholesterol (UniProt Consortium, 2017). As can be seen from Figure 5 , the 2 blocks are linked through the gene $R X R G$ (retinoid acid receptor RXR-gamma), suggesting that the 2 biological processes are interacting through this gene. Further noteworthy blocks of genes are the genes $P C, L D H A$, and $L D H B$, known to be involved in gluconeogenesis, and CYPrA1, CYP2C87, CYP26A1, $C Y P 2 U 1$, and CYP2C19, belonging to the cytochrome P450 (CYP) family (UniProt Consortium, 2017).

\section{CONCLUSIONS}

We investigated changes in the liver transcriptome from late gestation to early lactation to gain a deeper understanding of biological processes involved in metabolic adaptation. According to our knowledge, this is the first study to use RNA-seq to study metabolic adaptation without any experimental interventions (i.e., stimulation of $\mathrm{NEB}$ or special diets). We found $\sim 10 \%$ of the genes expressed in the liver to be differentially expressed after calving. The major results of the DGEA and GSEA were consistent with the literature and our current understanding of the transition cow, even 
though a substantial part of the significant genes were specific to our study compared with other studies on the transition cow without experimental interventions. Exploring the interactions between the significant genes, we visualized the relationships between biological processes important for metabolic adaptation in the form of an interacting network and identified key genes through which the processes are linked to each other. The discovered factors are a valuable contribution to the understanding of the metabolic adaptation and their biology should be more closely investigated.

\section{ACKNOWLEDGMENTS}

We thank Braunvieh Schweiz and Qualitas AG (Zug, Switzerland) for providing the data. This study was supported by a grant of the Swiss Commission for Technology and Innovation CTI (project no. 13948.2 PFLSLS) and Swissgenetics (Zollikofen, Switzerland). The Next Generation Sequencing Platform of the University of Bern is acknowledged for performing the sequencing experiment, and the Interfaculty Bioinformatics Unit of the University of Bern is thanked for providing computational infrastructure. We thank Michèle Ackermann and Muriel Fragnière (both from NextGenerationSequencing platform, Institute for Genetics, Vetsuisse Faculty, University of Bern, Bern, Switzerland) for expert technical assistance. The dataset supporting the conclusions of this article is available in the NCBI SRA repository (SRP066548; http://www.ncbi.nlm.nih.gov/ bioproject/PRJNA303131/).

\section{REFERENCES}

Akbar, H., F. Batistel, J. K. Drackley, and J. J. Loor. 2015. Alterations in hepatic FGF21, co-regulated genes, and upstream metabolic genes in response to nutrition, ketosis and inflammation in peripartal Holstein cows. PLoS One 10:e0139963. https://doi.org/ 10.1371/journal.pone.0139963.

Akbar, H., M. Bionaz, D. B. Carlson, S. L. Rodriguez-Zas, R. E. Everts, H. A. Lewin, J. K. Drackley, and J. J. Loor. 2013. Feed restriction, but not L-carnitine infusion, alters the liver transcriptome by inhibiting sterol synthesis and mitochondrial oxidative phosphorylation and increasing gluconeogenesis in mid-lactation dairy cows. J. Dairy Sci. 96:2201-2213. https://doi.org/10.3168/ jds.2012-6036.

Andrews, S. 2010. FastQC: A quality control tool for high throughput sequence data. http://www.bioinformatics.babraham.ac.uk/ projects/fastqc.

Benjamini, Y., and Y. Hochberg. 1995. Controlling the false discovery rate: A practical and powerful approach to multiple testing. J. R. Stat. Soc. Ser. B Methodol. 57:289-300.

Bernabucci, U., B. Ronchi, N. Lacetera, and A. Nardone. 2005. Influence of body condition score on relationships between metabolic status and oxidative stress in periparturient dairy cows. J. Dairy Sci. 88:2017-2026. https://doi.org/10.3168/jds.S0022 -0302(05)72878-2.

Bolger, A. M., M. Lohse, and B. Usadel. 2014. Trimmomatic: A flexible trimmer for Illumina sequence data. Bioinformatics 30:21142120. https://doi.org/10.1093/bioinformatics/btu170.
Carriquiry, M., W. J. Weber, S. C. Fahrenkrug, and B. A. Crooker. 2009. Hepatic gene expression in multiparous Holstein cows treated with bovine somatotropin and fed n-3 fatty acids in early lactation. J. Dairy Sci. 92:4889-4900. https://doi.org/10.3168/jds .2008-1676.

Deng, Q., G. Liu, L. Liu, Y. Zhang, L. Yin, X. Shi, J. Wang, X. Yuan, G. Sun, Y. Li, W. Yang, L. Guo, R. Zhang, Z. Wang, X. Li, and X. Li. 2015. BHBA influences bovine hepatic lipid metabolism via AMPK signaling pathway. J. Cell. Biochem. 116:1070-1079. https://doi.org/10.1002/jcb.25062.

Dobin, A., C. A. Davis, F. Schlesinger, J. Drenkow, C. Zaleski, S. Jha P. Batut, M. Chaisson, and T. R. Gingeras. 2013. STAR: Ultrafast universal RNA-seq aligner. Bioinformatics 29:15-21. https://doi .org/10.1093/bioinformatics/bts635.

Drackley, J. K., H. M. Dann, G. N. Douglas, N. A. J. Guretzky, N. B. Litherland, J. P. Underwood, and J. J. Loor. 2005. Physiological and pathological adaptations in dairy cows that may increase susceptibility to periparturient diseases and disorders. Ital. J. Anim. Sci. 4:323-344. https://doi.org/10.4081/ijas.2005.323.

Flicek, P. I. Ahmed, M. R. Amode, D. Barrell, K. Beal, S. Brent, D. Carvalho-Silva, P. Clapham, G. Coates, S. Fairley, S. Fitzgerald, L. Gil, C. Garcia-Giron, L. Gordon, T. Hourlier, S. Hunt, T. Juettemann, A. K. Kahari, S. Keenan, M. Komorowska, E. Kulesha, I. Longden, T. Maurel, W. M. McLaren, M. Muffato, R. Nag, B. Overduin, M. Pignatelli, B. Pritchard, E. Pritchard, H. S. Riat, G. R. S. Ritchie, M. Ruffier, M. Schuster, D. Sheppard D. Sobral, K. Taylor, A. Thormann, S. Trevanion, S. White, S. P. Wilder, B. L. Aken, E. Birney, F. Cunningham, I. Dunham, J. Harrow, J. Herrero, T. J. P. Hubbard, N. Johnson, R. Kinsella, A. Parker, G. Spudich, A. Yates, A. Zadissa, and S. M. J. Searle. 2013. Ensembl 2013. Nucleic Acids Res. 41:D48-D55. https://doi .org/10.1093/nar/gks1236.

Gene Ontology Consortium. 2015. Gene Ontology Consortium: Going forward. Nucleic Acids Res. 43:D1049-D1056. https://doi.org/10 $.1093 /$ nar/gku1179.

Graber, M., S. Kohler, T. Kaufmann, M. G. Doherr, R. M. Bruckmaier, and H. A. van Dorland. 2010. A field study on characteristics and diversity of gene expression in the liver of dairy cows during the transition period. J. Dairy Sci. 93:5200-5215. https://doi.org/ 10.3168/jds.2010-3265.

Greenfield, R. B., M. J. Cecava, and S. S. Donkin. 2000. Changes in mRNA expression for gluconeogenic enzymes in liver of dairy cattle during the transition to lactation. J. Dairy Sci. 83:1228-1236. https://doi.org/10.3168/jds.S0022-0302(00)74989-7.

Gross, J. H. A. van Dorland, R. M. Bruckmaier, and F. J. Schwarz. 2011a. Performance and metabolic profile of dairy cows during a lactational and deliberately induced negative energy balance with subsequent realimentation. J. Dairy Sci. 94:1820-1830. https://doi .org $/ 10.3168 / \mathrm{jds} .2010-3707$.

Gross, J., H. A. van Dorland, F. J. Schwarz, and R. M. Bruckmaier. 2011b. Endocrine changes and liver mRNA abundance of somatotropic axis and insulin system constituents during negative energy balance at different stages of lactation in dairy cows. J. Dairy Sci. 94:3484-3494. https://doi.org/10.3168/jds.2011-4251.

Gross, J. J., and R. Bruckmaier. 2015. Repeatability of metabolic responses to a nutrient deficiency in early and mid-lactation and its implication to robustness of dairy cows. J. Dairy Sci. 98:86348643. https://doi.org/10.3168/jds.2014-9246.

Ha, N.-T., J. J. Gross, A. van Dorland, J. Tetens, G. Thaller, M. Schlather, R. Bruckmaier, and H. Simianer. 2015. Gene-based mapping and pathway analysis of metabolic traits in dairy cows. PLoS One 10:e0122325. https://doi.org/10.1371/journal.pone .0122325 .

Ihnatova, I., and E. Budinska. 2015. ToPASeq: An R package for topology-based pathway analysis of microarray and RNA-Seq data. BMC Bioinformatics 16:350. https://doi.org/10.1186/s12859-015 -0763-1.

Kanehisa, M., S. Goto, Y. Sato, M. Furumichi, and M. Tanabe. 2012 KEGG for integration and interpretation of large-scale molecular data sets. Nucleic Acids Res. 40:D109-D114. https://doi.org/10 $.1093 / \mathrm{nar} / \mathrm{gkr} 988$. 
Kessel, S., M. Stroehl, H. H. D. Meyer, S. Hiss, H. Sauerwein, F. J. Schwarz, and R. M. Bruckmaier. 2008. Individual variability in physiological adaptation to metabolic stress during early lactation in dairy cows kept under equal conditions. J. Anim. Sci. 86:29032912. https://doi.org/10.2527/jas.2008-1016.

Kessler, E. C., J. J. Gross, R. M. Bruckmaier, and C. Albrecht. 2014. Cholesterol metabolism, transport, and hepatic regulation in dairy cows during transition and early lactation. J. Dairy Sci. 97:54815490. https://doi.org/10.3168/jds.2014-7926.

Khan, M. J., C. B. Jacometo, D. E. Graugnard, M. N. Corrêa, E. Schmitt, F. Cardoso, and J. J. Loor. 2014. Overfeeding dairy cattle during late-pregnancy alters hepatic PPAR $\alpha$-regulated pathways including hepatokines: Impact on metabolism and peripheral insulin sensitivity. Gene Regul. Syst. Bio. 8:97-111. https://doi.org/10 $.4137 /$ GRSB.S14116.

Kim, D., G. Pertea, C. Trapnell, H. Pimentel, R. Kelley, and S. L. Salzberg. 2013. TopHat2: Accurate alignment of transcriptomes in the presence of insertions, deletions and gene fusions. Genome Biol. 14:R36. https://doi.org/10.1186/gb-2013-14-4-r36.

Liao, Y., G. K. Smyth, and W. Shi. 2014. featureCounts: An efficient general purpose program for assigning sequence reads to genomic features. Bioinformatics 30:923-930. https://doi.org/10.1093/ bioinformatics/btt656.

Loor, J. J., H. M. Dann, R. E. Everts, R. Oliveira, C. A. Green, N. A. J. Guretzky, S. L. Rodriguez-Zas, H. A. Lewin, and J. K. Drackley. 2005. Temporal gene expression profiling of liver from periparturient dairy cows reveals complex adaptive mechanisms in hepatic function. Physiol. Genomics 23:217-226. https://doi.org/10.1152/ physiolgenomics.00132.2005.

McCabe, M., S. Waters, D. Morris, D. Kenny, D. Lynn, and C. Creevey. 2012. RNA-seq analysis of differential gene expression in liver from lactating dairy cows divergent in negative energy balance. BMC Genomics 13:193.

McCarthy, D. J., Y. Chen, and G. K. Smyth. 2012. Differential expression analysis of multifactor RNA-Seq experiments with respect to biological variation. Nucleic Acids Res. 40:4288-4297. https://doi .org/10.1093/nar/gks042.

Mills, G. C. 1957. Hemoglobin catabolism I. Glutathione peroxidase, an erythrocyte enzyme which protects hemoglobin from oxidative breakdown. J. Biol. Chem. 229:189-197.

Mosteller, F., and R. A. Fisher. 1948. Questions and answers. Am. Stat. 2:30-31. https://doi.org/10.2307/2681650.

Ostrowska, M., B. Ż. Górka, K. Słoniewski, and L. Z. Kowalski. 2013. Expression of PC, PCK1, PCK2, LDHB, FBP1 and G6PC genes in the liver of cows in the transition from pregnancy to lactation. Anim. Sci. Pap. Rep. 31:281-290.

R Core Team. 2014. R: A language and environment for statistical computing. R Foundation for Statistical Computing, Vienna, Austria.

Reynolds, C. K., P. C. Aikman, B. Lupoli, D. J. Humphries, and D. E. Beever. 2003. Splanchnic metabolism of dairy cows during the transition from late gestation through early lactation. J. Dairy Sci. 86:1201-1217. https://doi.org/10.3168/jds.S0022-0302(03)73704 -7 .

Robinson, M. D., D. J. McCarthy, and G. K. Smyth. 2010. edgeR: A Bioconductor package for differential expression analysis of digital gene expression data. Bioinformatics 26:139-140. https://doi.org/ 10.1093/bioinformatics/btp616

Schlegel, G., R. Ringseis, J. Keller, F. J. Schwarz, and K. Eder. 2012. Changes in the expression of hepatic genes involved in cholesterol homeostasis in dairy cows in the transition period and at different stages of lactation. J. Dairy Sci. 95:3826-3836.
Schlegel, G., R. Ringseis, J. Keller, F. J. Schwarz, W. Windisch, and K. Eder. 2013. Expression of fibroblast growth factor 21 in the liver of dairy cows in the transition period and during lactation. J. Anim. Physiol. Anim. Nutr. (Berl.) 97:820-829. https://doi.org/10 .1111/j.1439-0396.2012.01323.x.

Schurch, N. J., P. Schofield, M. Gierliński, C. Cole, A. Sherstnev, V. Singh, N. Wrobel, K. Gharbi, G. G. Simpson, T. Owen-Hughes, M. Blaxter, and G. J. Barton. 2016. How many biological replicates are needed in an RNA-seq experiment and which differential expression tool should you use? RNA 22:839-851. https://doi.org/ 10.1261/rna.053959.115.

Seyednasrollah, F., A. Laiho, and L. L. Elo. 2015. Comparison of software packages for detecting differential expression in RNA-seq studies. Brief. Bioinform. 16:59-70. https://doi.org/10.1093/bib/ bbt086.

Sharma, N., N. K. Singh, O. P. Singh, V. Pandey, and P. K. Verma. 2011. Oxidative stress and antioxidant status during transition period in dairy cows. Asian-australas. J. Anim. Sci. 24:479-484.

Sordillo, L. M., and S. L. Aitken. 2009. Impact of oxidative stress on the health and immune function of dairy cattle. Vet. Immunol. Immunopathol. 128:104-109. https://doi.org/10.1016/j.vetimm.2008 .10 .305 .

Subramanian, A., P. Tamayo, V. K. Mootha, S. Mukherjee, B. L. Ebert, M. A. Gillette, A. Paulovich, S. L. Pomeroy, T. R. Golub, E. S. Lander, and J. P. Mesirov. 2005. Gene set enrichment analysis: A knowledge-based approach for interpreting genome-wide expression profiles. Proc. Natl. Acad. Sci. USA 102:15545-15550. https://doi.org/10.1073/pnas.0506580102.

Szklarczyk, D., A. Franceschini, S. Wyder, K. Forslund, D. Heller, J. Huerta-Cepas, M. Simonovic, A. Roth, A. Santos, K. P. Tsafou, M. Kuhn, P. Bork, L. J. Jensen, and C. von Mering. 2015. STRING v10: Protein-protein interaction networks, integrated over the tree of life. Nucleic Acids Res. 43:D447-D452. https://doi.org/10.1093/ nar/gku1003.

Tarca, A. L., S. Draghici, P. Khatri, S. S. Hassan, P. Mittal, J. Kim, C. J. Kim, J. P. Kusanovic, and R. Romero. 2009. A novel signaling pathway impact analysis. Bioinformatics 25:75-82. https://doi .org/10.1093/bioinformatics/btn577.

UniProt Consortium. 2017. UniProt: The universal protein knowledgebase. Nucleic Acids Res. 45:D158-D169. https://doi.org/10.1093/ nar/gkw1099.

van Dorland, H. A., S. Richter, I. Morel, M. G. Doherr, N. Castro, and R. M. Bruckmaier. 2009. Variation in hepatic regulation of metabolism during the dry period and in early lactation in dairy cows. J. Dairy Sci. 92:1924-1940. https://doi.org/10.3168/jds.2008-1454.

Xi, Y. M., Z. Yang, F. Wu, Z. Y. Han, and G. L. Wang. 2015. Gene expression profiling of hormonal regulation related to the residual feed intake of Holstein cattle. Biochem. Biophys. Res. Commun. 465:19-25.

Zhang, X., X. Xie, B. L. Heckmann, A. M. Saarinen, T. A. Czyzyk, and J. Liu. 2014. Targeted disruption of G0/G1 switch gene 2 enhances adipose lipolysis, alters hepatic energy balance, and alleviates high-fat diet-induced liver steatosis. Diabetes 63:934-946. https://doi.org/10.2337/db13-1422.

Zimin, A. V., A. L. Delcher, L. Florea, D. R. Kelley, M. C. Schatz, D. Puiu, F. Hanrahan, G. Pertea, C. P. Van Tassell, T. S. Sonstegard, G. Marçais, M. Roberts, P. Subramanian, J. A. Yorke, and S. L. Salzberg. 2009. A whole-genome assembly of the domestic cow, Bos taurus. Genome Biol. 10:R42. https://doi.org/10.1186/ gb-2009-10-4-r42. 